\title{
LOCAL PREMIUM OR LOCAL DISCOUNT: THE CASE OF PACKAGED FRESH TOMATOES IN HAWAII
}

\author{
XUN XU \\ Department of Natural Resources and Environmental Management, University of Hawaii at Manoa, Honolulu, Hawaii \\ Department of Economics, University of Hawaii at Manoa, Honolulu, Hawaii \\ KRISTOPHER KEAHIOLALO \\ Department of Natural Resources and Environmental Management, University of Hawaii at Manoa, Honolulu, Hawaii \\ Department of Economics, University of Hawaii at Manoa, Honolulu, Hawaii

\section{MATTHEW K. LOKE} \\ Department of Natural Resources and Environmental Management, University of Hawaii at Manoa, Honolulu, Hawaii \\ Hawaii Department of Agriculture, Agricultural Development Division, Honolulu, Hawaii \\ PINGSUN LEUNG* \\ Department of Natural Resources and Environmental Management, University of Hawaii at Manoa, Honolulu, Hawaii
}

\begin{abstract}
This article utilizes the 2011 Nielsen scanner data for the Honolulu fresh tomato market to explore the existence of price premium for local food. Hedonic analysis is conducted to delineate the price impact of the local attribute. Contrary to the widely perceived local price premium in the consumer preference literature, mixed results of price premiums and discounts are discovered for local tomato products. Additional investigation suggests that the prices of local tomatoes are likely influenced by seasonal output fluctuation. The limited market distribution capacity facing local producers may have contributed further to the retail discounting.
\end{abstract}

Keywords. Elasticity of substitution, hedonic price model, local product, price premium, revealed preference, scanner data, weighted least squares

JEL Classifications. L11, L81, M31, Q11, Q13

The authors gratefully acknowledge the support of the Hawaii Department of Agriculture; the College of Tropical Agriculture and Human Resources, University of Hawaii at Manoa, under the Research Supplemental Funds Program (award no. HAW01122-H); and the U.S. Department of Agriculture, Agriculture and Food Research Initiative Competitive Grant Program (nos. 2011-67023-30033 and 2014-67023-21805) from the National Institute of Food and Agriculture. Responsibility for the final content rests with the authors.

*Email: psleung@hawaii.edu 


\section{Introduction}

After "buying organic," "buying local" seems to be the next big thing in food marketing. ${ }^{1}$ Across North America, cultural trends such as the "locavore" and "farm-to-table" movements enjoy growing popularity. Likewise, the number and popularity of farmers markets have skyrocketed in recent years, becoming not only a regular weekly shopping stop for residents but also a great tourist destination for visitors. These examples demonstrate the high demand for local products, reflecting consumers' increasing concern for food safety and the environmental impact of the food supply system (Thilmany, Bond, and Bond, 2008). What further promotes the growing demand is the "local" campaign by a number of retailers such as Walmart, Whole Foods, and Safeway to increase the availability of local produce.

Despite the growing interest in local foods, there is still a lack of empirical evidence demonstrating that consumers are paying more for "local." Most existing literature focuses on the study of consumers' willingness-to-pay (WTP) for local products from the demand perspective. Using the common approach of contingent valuation $(\mathrm{CV})$ with hypothetical survey data, many studies find a positive price premium for local food in their examination of consumers' stated preference (Brown, 2003; Carpio and Isengildina-Massa, 2009; Darby et al., 2008; Giraud, Bond, and Bond, 2005; Grebitus, Lusk, and Nayga, 2013; Loureiro and Hine, 2002; Ulupono Initiative, 2011). However, this approach has been criticized by some researchers because of the concern of incentive incompatibility (Cummings, Harrison, and Rutström, 1995), which could result in potential overestimation of WTP. For example, Buzby and Skees (1994) provide supporting evidence with respect to organic food that stated preference based on hypothetical surveys may not always translate into actual purchasing behavior.

Another popular approach to investigate consumers' WTP for local food is the experimental auction (EA; see, e.g., Akaichi, Gil, and Nayga, 2012; Gracia, de Magistris, and Nayga, 2012). Compared with CV, the EA mechanism provides incentives for subjects to report their real WTP for the products. Researchers have shown that when hypothetical survey and EA methods are both applied to the same product, the latter yields substantially lower WTP results (see, e.g., Alfnes and Rickertsen, 2003). Hence, between these two approaches, it is likely that the EA estimates are closer to consumers' real valuation of the product.

Still, in more realistic market settings, the implications of the WTP studies remain to be empirically tested. This is because consumers' actual purchasing behavior is not only determined by consumer demand but may also be influenced

1 A recent national consumer survey conducted by market research publisher Package Facts estimates that local foods generated $\$ 12$ billion in sales in 2014, accounting for $2 \%$ of total food retail sales in the United States (QSR, 2015). Package Facts further anticipates local foods will grow faster than total food sales in the next 5 years and approach $\$ 20$ billion in 2019 . 
by other conditions such as market supply of that particular product and its substitutes. For example, Umberger, Thilmany McFadden, and Smith (2009) and Gracia, de Magistris, and Nayga (2012), utilizing CV and EA methods, respectively, found that in addition to personal benefits, other factors such as altruism and social influence also impacted consumers' WTP for local food. While using scanner data based on market transaction records, Xu, Loke, and Leung (2015) found that prices of local and imported lettuce products in the Hawaii market were well explained by basic product attributes such as quality, type, and weight. In other words, consumers were not paying a price premium for local products because of additional motivations.

Therefore, more empirical research is needed to understand the real price characteristics of the local attribute. Henceforth, this article attempts to explore the existence of local premium in real market situations by explicitly analyzing consumers' revealed preference using scanner data sourced from actual retail transactions. Market prices are examined for local and imported fresh tomato products in the Honolulu metropolitan market area. The hedonic modeling approach is applied to delineate the price impact of the local attribute along with other product attributes. Armington elasticity of substitution is also estimated to measure the degree of substitutability between local and imported tomatoes.

One interesting aspect of the Hawaii fresh tomato market is that local products by weight account for more than three-quarters of the entire market. This provides an unusual opportunity to examine the role of local supply as a potentially important determinant of local food prices, considering that local food in general amounts to a small market share in the United States (Low and Vogel, 2011). Local production may influence market prices through fluctuations during the peak and off-peak seasons. This supply-side implication of the "local" attribute is explored in this article.

Another distinct feature of the Hawaii market is its geographic and cultural settings, which provide a clear separation from other market areas. As often mentioned in the literature, no consensus has been reached on a clear definition of "local" (see, e.g., Martinez et al., 2010). According to the 2008 Farm Act, the maximum farm-to-table distance for local food is 400 miles. Alternately, some strict locavores have defined "local" as within the radius of 100 miles from where the farm grows food to where it is ultimately consumed (Roosevelt, 2006). Still, a third commonly adopted definition in the literature for local is "within state" (Carpio and Isengildina-Massa, 2009; Loureiro and Hine, 2002). These conflicting standards may give rise to confusing policy implications and limit potential application of the results (e.g., for border cities such as St. Louis, Missouri, and East St. Louis, Illinois). In Hawaii, "local food" explicitly refers to all food grown in the Hawaiian Islands, which is in clear contrast to "imported food" sourced from continental United States or elsewhere. According to Loke and Leung (2013), the Hawaii food market is similar in nature to many other market areas in the continental United States, with most food 
being imported. Hence, a unique opportunity is present to study the local food market.

\section{Description of the Data}

Scanner data have been successfully applied to study attributes of a number of food products, including frozen fish (Roheim, Asche, Santos, 2011; Roheim, Gardiner, and Asche, 2007), eggs (Kim and Chung, 2011; Lusk, 2010), tomatoes (Keahiolalo, 2013), and so forth. The Nielsen scanner data set in this study is sourced from three major grocery chains with a total of 19 stores in the Honolulu metropolitan area. It tracks prices, sales units, and select attributes of various products organized by stock-keeping units (SKUs) on a weekly basis in 2011.

Information collected in each store is aggregated into 52 observations of average prices and other variables for each product. Random weight (or loose weight) items are not included in the data set because their SKUs are not consistent across purchases or stores and therefore are not compiled. A total of 1,279 fresh tomato products with consistent SKUs are furnished in the original data set. Products that recorded zero sales during the entire year are removed, leaving 40 SKUs with 1,174 observations. These products are classified as grape and cherry tomato, regular tomato, and other ${ }^{2}$ tomato, which represent $42.41 \%$, $26.21 \%$, and $31.38 \%$ of total sample weight, respectively.

Other available product attributes include producer information, product weight, weekly sales value, weekly sales units, and organic origin. Information on product quality is desired for this analysis but is not available. Organic tomatoes constitute $3.7 \%$ of all tomatoes by weight. All local tomatoes are actively marketed by the three grocery chains. In the stores, highly visible shelf tags such as "Hawaii Grown," "Local," and "Locally Grown" are displayed to capture the attention of consumers seeking to purchase local food. Among the 40 products with sales records, 11 are locally sourced, accounting for $57 \%$ of the sample by weight. As noted previously, local products occupy the majority share of the Hawaii fresh tomato market. Total local production between 2007 and 2011 amounts to $77 \%$ of the entire market supply. Hence, the data sample in this study, which covers packaged tomatoes, is roughly consistent with the entire Hawaii market, in the sense that local products have more than half of the market share.

Table 1 provides a detailed description of the data. Most statistics match intuition. Regular tomatoes are on average less expensive than grape and cherry as well as other tomatoes. Local products are present in all three categories. One interesting observation is the consistent price discount in all categories (except regular) for local tomatoes, which seems to disagree with the finding of

2 Other tomatoes include the following types: baby roma, campari, currant, family, golden, kumato, medley, vine ripe, yellow sweet, and so forth. Regular tomato refers to the usual "slicing" tomato. 
Table 1. Descriptive Statistics of Tomato Data Set

\begin{tabular}{lrrr}
\hline \hline & Average Price per Pound & Market Share (weight) & Price Premium \\
\hline Grape and cherry & 7.39 & & 0.00 \\
All & 6.49 & $100.00 \%$ & -0.90 \\
Local & 7.60 & $29.70 \%$ & 0.21 \\
Import all & 6.73 & $70.30 \%$ & -0.66 \\
Import nonorganic & 8.67 & $61.58 \%$ & 1.28 \\
Organic & & $8.72 \%$ & 0.00 \\
Regular & 3.90 & & 0.00 \\
All & 3.90 & $100.00 \%$ & 0.00 \\
Local & & $100.00 \%$ & -0.21 \\
Other & 7.25 & $100.00 \%$ & 0.18 \\
All & 7.04 & $58.00 \%$ & 0.18 \\
Local & 7.44 & $42.00 \%$ & 0.00 \\
Import all & 7.44 & $42.00 \%$ & -0.87 \\
Import nonorganic & & & 0.58 \\
All tomatoes & 6.96 & $100.00 \%$ & 0.15 \\
All & 6.09 & $57.00 \%$ & 1.71 \\
Local & 7.54 & $43.00 \%$ & $39.30 \%$ \\
Import all & 7.11 & $3.70 \%$ & \\
Import nonorganic & 8.67 & & \\
Organic & & & \\
\hline \hline
\end{tabular}

Note: Price premium is calculated as the difference between the average price per pound of a specific subcategory and its overall category average.

the consumer preference literature. As the summary statistics average out price impacts of various product characteristics, a hedonic price model is next applied to analyze the determinants of price variations and better estimate the effects of the local attribute.

\section{Methodology}

\subsection{Hedonic Price Model}

One shortfall of the classic microeconomic theory based on consumers maximizing utility and producers maximizing profit is the lack of an effective mechanism for determining the intrinsic value of a product's attributes because these attributes are not traded directly. Under the hedonic hypothesis, individual products themselves do not provide a consumer utility but instead are seen as bundles of individually valued attributes, and the value of a product is based on the utility delivered by these attributes. The hedonic price analysis offers a method to estimate the impact of individual attributes on retail prices. Early adopters such as Becker (1965), Lancaster (1966), and Muth (1966) attribute these values strictly as consumers' value of these attributes. Rosen (1974) extends 
this into the more widely accepted view that the revealed values are market equilibria representing both consumer preferences and producer costs.

The analytical framework of this article is based on Rosen's hedonic price theory. Products in the market are described by $n$ objectively measured characteristics and, therefore, can be fully represented by the vector $z=\left(z_{1}, \ldots\right.$, $z_{n}$ ), where $z_{j}$ describes the $j$ th attribute of the product. It is assumed that there exists a sufficiently large variety, but not necessarily every combination, of potential packages of attributes in the marketplace. Prices for products are then interpreted as functions of the bundled characteristics; in particular, the price $p_{i}$ of product $i$ is $p_{i}\left(z_{1}, \ldots, z_{n}\right)$. Perfect competition is assumed where producers and consumers are price takers with perfect information of the market. Therefore, prices are revealed in the market through the usual mechanisms of individual consumer utility maximization, producer profit maximization, and market clearing conditions. In this framework, estimated hedonic price effects are not interpreted as identifying the structure of consumer preferences or producer technologies but instead are generated through a joint-envelope function of supply and demand.

In recent hedonic literature, linear and log-linear forms are the two most commonly used in hedonic price analysis because they provide a straightforward interpretation of their results. A Box-Cox transformation is first performed but does not indicate a favorable functional form. ${ }^{3}$ Hence, we follow Diewert (2003) and use a log-linear model for estimation, in which results are interpreted as percentage changes in price. The model takes the following form:

$$
\begin{aligned}
\ln \left(p_{i}\right)= & \mathrm{a}+\mathrm{b} \times \text { local }_{i}+\mathrm{c} \times \text { organic }_{i}+\Sigma_{j} \beta_{j} \times \text { type }_{j i}+\mathrm{d} \times \ln \left(\text { pkgsize }_{i}\right) \\
& +\Sigma_{k} \theta_{k} \times \text { season }_{k i}+e_{i}
\end{aligned}
$$

where $j$ indexes the type of tomato, $k$ indexes the seasons, and $e_{i}$ is a random error. The dependent variable is logarithm of price per pound. Independent variables include dummy variables for local, organic, product type, and seasons. Because a number of untypical package sizes are available, product weight is transformed into logarithm form. The inclusion of the constant term allows the coefficients to be interpreted as the percent deviation from the baseline product.

The usual peak production season for local tomatoes in Hawaii is from May to September (Hawaii Department of Agriculture, 2013), which roughly corresponds to week 19 through week 40 in the data. To factor in the potential impact of seasonal fluctuation in local supply and other possible factors, dummy variables are generated to represent the time period before, during, and after the local peak season. Table 2 provides descriptions of the variables used in the regressions. For this analysis, imported nonorganic grape and cherry tomatoes sold in season 1 (before the peak season) are chosen as the reference product.

3 We thank one anonymous referee for suggestion of the Box-Cox analysis. 
Table 2. Descriptions of Variables in Hedonic Regressions

\begin{tabular}{llcc}
\hline \hline Variable & Description & Mean & $\begin{array}{c}\text { Standard } \\
\text { Deviation }\end{array}$ \\
\hline pricelb & Average weekly price per pound in dollars & 6.965 & 2.330 \\
pkgsize & Package size in pounds & 0.768 & 0.166 \\
local & $=1$ if product is a local tomato, =0 otherwise & 0.398 & 0.490 \\
organic & $=1$ if product is an organic tomato, =0 otherwise & 0.165 & 0.371 \\
grape and cherry & $=1$ if product is a grape or cherry tomato, =0 otherwise & 0.450 & 0.498 \\
regular & $=1$ if product is a regular tomato, =0 otherwise & 0.106 & 0.308 \\
other & $=1$ if product is another tomato, =0 otherwise & 0.444 & 0.497 \\
season1 & $=1$ if before local peak season, =0 otherwise & 0.343 & 0.475 \\
season2 & $=1$ if during local peak season, =0 otherwise & 0.430 & 0.495 \\
season3 & $=1$ if after local peak season, =0 otherwise & 0.228 & 0.419 \\
\hline \hline
\end{tabular}

Diewert (2003) points out that weighted models are preferred to unweighted ones because the results would be more representative of the data and the market. In an unweighted model, a fresh tomato SKU with 100 annual unit sales would have as much influence as one with 10,000 annual unit sales, which is not representative. Also, value weighting is preferred to sales unit weighting because sales unit weights will give too little weight to higher-valued SKUs and too much weight to cheaper-priced SKUs. Therefore, additional specifications are run using weighted least squares (WLS) where weekly observations are weighted by the square root of revenue that the SKU generated that week.

Because the data contain transaction records over a 52-week period, one concern is that the average retail prices of a product from week to week are not independent events. To get around this issue, weekly observations are combined to pull out the annual average unit price and price per pound for each SKU. Although this leaves only 1 observation per SKU, or 40 observations, and reduces the degrees of freedom, it is thought that the regression using the annual average prices would provide a robustness check to the benchmark specification.

\subsection{Armington Elasticity of Substitution}

To estimate the substitutability between local and imported products, we compute the (Armington) elasticity of substitution, which is commonly reported in international trade literature as a measure of consumers' willingness to substitute imported products for domestic equivalents (and vice versa) in the face of a change in their relative prices. Following the Armington (1969) framework, products are differentiated by production origin. Hence, local and imported products are treated as substitutes in consumption. The consumers' utility function takes the form of constant elasticity of substitution:

$$
Q=\left[\beta M^{(\sigma-1) / \sigma}+(1-\beta) L^{(\sigma-1) / \sigma}\right]^{\sigma /(\sigma-1)},
$$


where $M$ is the quantity of imported product; $L$ is the quantity of local product; $\beta$ is the distribution parameter; and $\sigma$ is the elasticity of substitution coefficient between the local and imported products, which is the primary variable of interest. The consumers' problem is to maximize the composite utility $Q$ given the prices of imported and local products $P_{M}$ and $P_{L}$. First-order condition of this utility maximization problem renders the following equation:

$$
M / L=\left\{\left[(\beta /(1-\beta)]\left(P_{L} / P_{M}\right)\right\}^{\sigma},\right.
$$

where import to local ratio can be expressed as a function of their price ratio. Taking the logarithm of this equation, one can obtain an estimation equation:

$$
Y=\alpha+\sigma X+\varepsilon
$$

where $Y=\ln (M / L) ; X=\ln \left(P_{L} / P_{M}\right) ; \alpha$ and $\sigma$ are the coefficients to be estimated, with $\sigma$ being the Armington elasticity of substitution between local and imported tomato; and $\varepsilon$ is the usual random error.

\section{Results and Discussion}

Table 3 reports the results of the model across various specifications using WLS. ${ }^{4}$ The first column provides estimates under the benchmark specification. ${ }^{5}$ Similar to the finding of the summary statistics, local tomatoes show an average of $10 \%$ price discount over the imported ones. Organic tomatoes, on the other hand, display a $20.8 \%{ }^{6}$ price premium. Among the three types of tomatoes, the other category is $17.23 \%$ more expensive than the baseline grape and cherry tomatoes, whereas the regular tomatoes are $7.96 \%$ cheaper. As expected, a negative coefficient for $\ln$ (pkgsize) is found, suggesting that a $1 \%$ increase in package size would result in a $0.847 \%$ decrease in price per pound. Compared with season 1 (before the peak season), season 2 (peak season) exhibits a $13.06 \%$ price discount, followed by a slight discount in season 3 (after the peak season). Nearly all coefficients are significant at the $1 \%$ level. The model is able to capture more than half of the price variation, suggesting a relatively good fit of the data.

In the second column, weekly observations are combined to create one annual observation per SKU. It is interesting to find that coefficient estimates of most variables are quite comparable to the previous model, although there has been some drop in statistical significance of the results. Discounts for local products and premiums for organic products remain at a similar level respectively. The coefficient of regular tomatoes loses significance. Despite the aggregate nature of

4 Ordinary least-squares results are not reported because the results are not significantly different in magnitude.

5 Following the suggestion of one anonymous referee, studentized residuals of the regressions are calculated, resulting in the removal of one outlier observation. The current result excludes the outlier.

6 Accurate percentage price changes are computed and reported using the formula $100\left(e^{\beta}-1\right)$, where $\beta$ is the estimated coefficient. 
Table 3. Results of Hedonic Regressions with Weighted Least Squares

\begin{tabular}{lcc}
\hline \hline In(pricelb) & (1) Seasonal Dummies & $(2)$ Annual \\
\hline local & $-0.100^{* * *}$ & $-0.127^{*}$ \\
& $(0.016)$ & $(0.067)$ \\
organic & $0.189^{* * *}$ & $0.220^{* *}$ \\
& $(0.025)$ & $(0.101)$ \\
regular & $-0.083^{* * *}$ & -0.002 \\
& $(0.027)$ & $(0.115)$ \\
other & $0.159^{* * *}$ & $0.172^{* *}$ \\
& $(0.015)$ & $(0.065)$ \\
ln(pkgsize) & $-0.847^{* * *}$ & $-0.828^{* * *}$ \\
& $(0.040)$ & $(0.159)$ \\
season2 & $-0.140^{* * *}$ & \\
& $(0.015)$ & \\
season3 & $-0.036^{* *}$ & $1.538^{* * *}$ \\
& $(0.018)$ & $(0.070)$ \\
constant & $1.644^{* * *}$ & 0.6174 \\
Adjusted $\mathrm{R}^{2}$ & $(0.020)$ & 40 \\
Observations & 0.5525 & \\
\hline \hline
\end{tabular}

Note: Asterisks (***, ${ }^{* *}$, and ${ }^{*}$ ) denote $P<0.01, P<0.05$, and $P<0.1$, respectively.

Table 4. Estimates of Armington Elasticity of Substitution (generalized least squares)

\begin{tabular}{lcc}
\hline \hline & Local versus Import Nonorganic & Organic versus Import Nonorganic \\
\hline Elasticity & 1.604 & 1.895 \\
Standard error & $(0.152)$ & $(0.195)$ \\
Durbin-Watson & 2.088 & 2.104 \\
$R^{2}$ & 0.6948 & 0.6593 \\
Observations & 51 & 51 \\
\hline \hline
\end{tabular}

the combined data, the model is able to capture a considerable portion of price variation in the data. This serves as a good indication of the robustness of the benchmark estimates.

Two sets of the Armington elasticity are calculated respectively for local/import nonorganic tomatoes and organic/import nonorganic tomatoes. An ordinary least-squares model is initially employed. The Durbin-Watson statistics reject the null hypothesis of no autocorrelation in both cases. To correct for autocorrelation, a generalized least-squares model is then utilized, with the results reported in Table 4. The final estimates of the composite elasticity are 1.604 and 1.895, respectively. Note that although elasticity valued between zero and one would imply a complementary relationship, these estimates suggest that both local and organic tomatoes are quite substitutable to the conventional imported nonorganic tomatoes. 


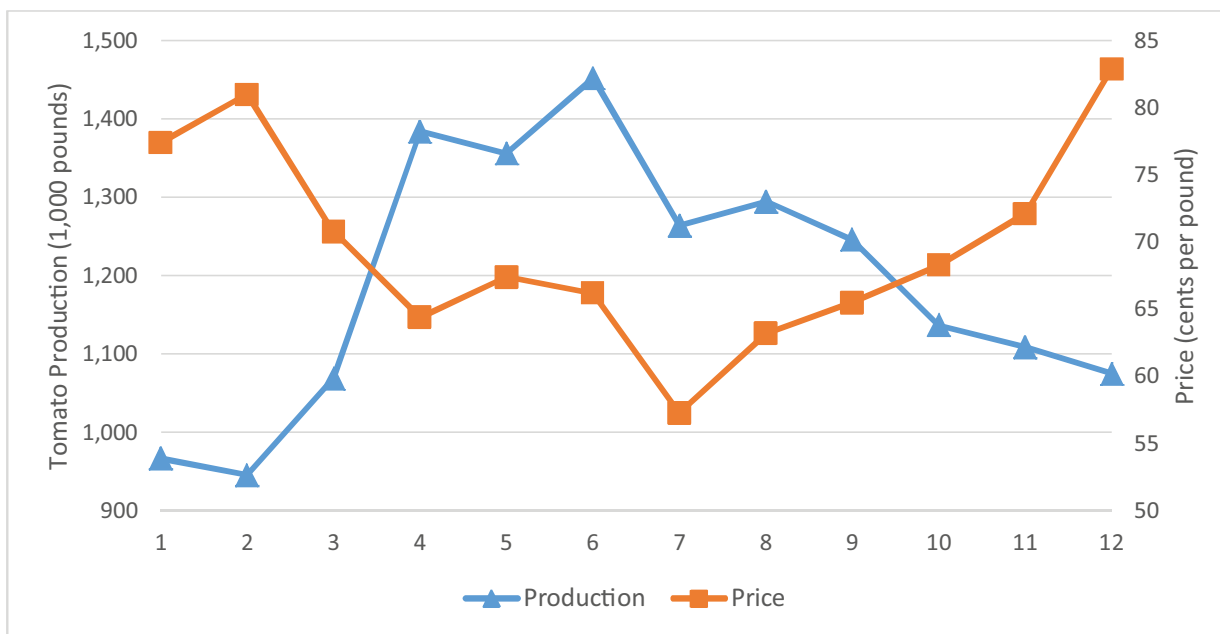

Figure 1. 2007 Hawaii Tomato Production and Farmgate Prices by Month (from National Agricultural Statistics Service [2011]; 2007 is the most recent year for which data are available)

The summary statistics and hedonic regressions based on the scanner data both identify a price discount for local tomatoes. This result clearly contrasts with the positive price premium reported in previous WTP research, such as that reported by the Ulupono Initiative (2011), which finds that Hawaii consumers are willing to pay $\$ 2.50$ per pound more for local tomatoes. In terms of organic premium, the result here is similar in magnitude to values reported by Huang and Lin (2007) for four regional markets in the United States (between 7\% and $17 \%$ ). The price discount during season 2 indicates that a surge in local production may impose a strong downward effect on market prices. Similar findings have been reported by Pirog and McCann (2009) for Iowa that prices of local zucchini and summer squash are becoming more competitive during peak seasons. For Hawaii, Figure 1 shows the relationship between monthly production and farmgate prices of fresh tomatoes in 2007. The farmgate price follows a clear opposite direction to total production. A simple regression also estimates that a $1 \%$ increase in total production could reduce the price by $0.59 \%$, with the result being significant at the $1 \%$ level.

To further decompose the correlation between local, seasonality, and other product attributes, interaction terms of local and other variables (product type, package size, and seasonality) are added to the benchmark specification. ${ }^{7}$ The

7 We thank two anonymous referees for this suggestion. Note that the interaction term of local and organic is not added because all local tomatoes are nonorganic. Interaction of local and package size is dropped because coefficient is insignificant. 
Table 5. Local Premium/Discount across Product Types and Seasons (weighted least squares)

\begin{tabular}{lccc}
\hline \hline & Season 1 & Season 2 & Season 3 \\
\hline Grape and cherry & $0.167^{* * *}$ & -0.029 & 0.035 \\
Other & $-0.083^{* * *}$ & $-0.279^{* * *}$ & $-0.215^{* * *}$ \\
\hline \hline
\end{tabular}

Note: Asterisks $\left({ }^{* * *},{ }^{* *}\right.$, and ${ }^{*}$ ) denote $P<0.01, P<0.05$, and $P<0.1$, respectively.

regression would then show how local price premium/discount varies across product types and seasons. A series of regressions are conducted, with reference product being different type/season combinations. The price difference between the baseline imported product and the local product for that type and season could then be directly tested using the reported $t$ statistics. The key results are shown in Table 5 .

It can be seen that local price premiums/discounts vary depending on product type and season. For grape and cherry tomatoes, there is an $18.18 \%$ local premium during season 1 (before the peak season). However, starting from season 2 (local peak season), price difference declines and becomes insignificant. On the other hand, there are constant local discounts for other tomatoes throughout the year, although prices are considerably lower in seasons 2 and 3. Comparing the results for both types of product, there is a clear downward effect on prices of local tomatoes during the peak production season, suggesting that market prices are likely influenced by the local production level.

One further contributing factor to the price discounting may be the capacity limitations in marketing and distribution by local producers in Hawaii. Since large national producers with more marketing and logistics competence have access to a larger market, production surpluses can be spread over more market areas with less need for discounting. In comparison, small local farms are often constrained by lack of distribution channels and market outlets (Martinez et al., 2010). In the case of Hawaii, because local tomatoes are exclusively supplied to the Hawaiian Islands, this may result in discounting at the retail level in times of production surplus.

Lastly, the Armington analysis shows that consumer choices with respect to locality and organic origins are elastic, and that both local and organic tomatoes are quite substitutable to import nonorganic tomatoes. The comparison of the two estimated values indicates that the local/import nonorganic product distinction may be slightly more manifest, which could be because local tomatoes have much larger market share than import organic tomatoes. From the local producers' perspective, because consumer demand appears sensitive to price changes, price discounting may be a viable competing strategy to acquire larger market share. 


\section{Conclusion}

This article evaluates the implicit price of the local attribute through the investigation of consumers' revealed preference in the Honolulu fresh tomato market. Hedonic price models and Nielsen scanner data are utilized to delineate the partial effect of "local." Contrary to the widely perceived local premium in numerous consumers' stated preference studies, we find that prices of local tomatoes produced in Hawaii are on average lower than their imported counterparts. Additional investigation reveals mixed results across product types and seasons: during the pre-peak production season, there is an $18.18 \%$ price premium for local grape and cherry tomatoes, whereas a $7.96 \%$ price discount is present for local other tomatoes. The local peak season seems to exert a strong downward pressure on prices of both types of local tomatoes through the rest of the year. Price difference becomes insignificant for grape and cherry, whereas price discount grows considerably larger for the other category. The limited marketing and distribution capacity of local producers as well as inadequate market outlet may have added to the retail discounting. The Armington analysis shows that consumer demand is quite elastic with respect to products of different origins.

These results provide useful implications to local food industry players. The hedonic regressions suggest that local producers may adjust production schedules and product strategies to improve profit. Additional investment in marketing and distributional networks may also be needed to facilitate the supply of local products to a larger market range. Moreover, the relatively high substitutability indicates that more marketing efforts are needed to increase consumer awareness of the benefits (freshness and nutrition) of local food and hence make it more distinguishable. In the meantime, the current high substitution elasticity also implies that price discounting may be a useful strategy to gain more market share.

Moving forward, future research can explore other commodities and market areas because product pricing will depend on product characteristics and local market conditions. Moreover, the majority of U.S. farms involved in local food sales likely rely on direct-to-consumer marketing such as farmers markets, community supported agriculture, and so forth (Low and Vogel, 2011). Because this article focuses on the intermediated marketing channel, investigation of consumer demand for local food in alternative sales networks would be another important step in advancing the understanding of the local food system.

\section{References}

Akaichi, F., J.M. Gil, and R.M. Nayga. "Assessing the Market Potential for a Local Food Product: Evidence from a Non-Hypothetical Economic Experiment." British Food Journal 114(2012):19-39. 
Alfnes, F., and K. Rickertsen. "SC-X: Calibrating Stated Choice Surveys with Experimental Auction Markets." Paper presented at the 25th International Conference of Agricultural Economists, Durban, South Africa, August 16-22, 2003.

Armington, P.S. "A Theory of Demand for Products Distinguished by Place of Production." Staff Papers (International Monetary Fund) 16(1969):159-78.

Becker, G.S. “A Theory of the Allocation of Time.” Economic Journal 75(1965):493-517.

Brown, C. "Consumers' Preferences for Locally Produced Food: A Study in Southeast Missouri." American Journal of Alternative Agriculture 18(2003):213-24.

Buzby, J.C., and J.R. Skees. "Consumers Want Reduced Exposure to Pesticides on Food." Food Review 17(1994):19-22.

Carpio, C.E., and O. Isengildina-Massa. "Consumer Willingness to Pay for Locally Grown Products: The Case of South Carolina.” Agribusiness 25 (2009):412-26.

Cummings, R.G., G.W. Harrison, and E.E. Rutström. "Homegrown Values and Hypothetical Surveys: Is the Dichotomous Choice Approach Incentive-Compatible?" American Economic Review 85(1995):260-66.

Darby, K., M.T. Batte, S. Ernst, and B. Roe. "Decomposing Local: A Conjoint Analysis of Locally Produced Foods." American Journal of Agricultural Economics 90(2008):47686.

Diewert, E. "Hedonic Regressions: A Review of Some Unresolved Issues.” Paper presented at the 7th Meeting of the Ottawa Group, Paris, May 27-29, 2003.

Giraud, K.L., C.A. Bond, and J.J. Bond. "Consumer Preferences for Locally Made Specialty Food Products across Northern New England.” Agricultural and Resource Economics Review 34(2005):204-16.

Gracia, A., T. de Magistris, and R.M. Nayga Jr. "Importance of Social Influence in Consumers' Willingness to Pay for Local Food: Are There Gender Differences?" Agribusiness 28(2012):361-71.

Grebitus, C., J.L. Lusk, and R.M. Nayga Jr. "Effect of Distance of Transportation on Willingness to Pay for Food." Ecological Economics 88(2013):67-75.

Hawaii Department of Agriculture. "Island Fresh Hawaii Seasonality Chart." 2013. Internet site: http://hdoa.hawaii.gov/add/files/2013/01/BLIM-poster12.pdf (Accessed April 1, 2015).

Huang, C. L. and Lin, B. "A Hedonic Analysis of Fresh Tomato Prices among Regional Markets." Review of Agricultural Economics 29(2007):783-800.

Keahiolalo, K. "Hedonic Price Analysis of Fresh Packaged Tomatoes in the Honolulu Market: An Exploratory Investigation.” Master's thesis, Department of Economics, University of Hawaii at Manoa, 2013.

Kim, C., and C. Chung. "Hedonic Analysis of Retail Egg Prices Using Store Scanner Data: An Application to the Korean Egg Market." Journal of Food Distribution Research 42(2011):14-27.

Lancaster, K.J. “A New Approach to Consumer Theory.” Journal of Political Economy 74(1966):132-57.

Loke, M.K., and P. Leung. "Hawai'i’s Food Consumption and Supply Sources: Benchmark Estimates and Measurement Issues.” Agricultural and Food Economics 1(2013):10.

Loureiro, M.L., and S. Hine. "Discovering Niche Markets: A Comparison of Consumer Willingness to Pay for Local (Colorado Grown), Organic, and GMO-Free Products.” Journal of Agricultural and Applied Economics 34(2002):477-87.

Low, S.A., and S. Vogel. Direct and Intermediated Marketing of Local Foods in the United States. Washington, DC: U.S. Department of Agriculture, Economic Research Service, Economic Research Report No. 128, 2011. 
Lusk, J.L. "The Effect of Proposition 2 on the Demand for Eggs in California." Journal of Agricultural \& Food Industrial Organization 8(2010):1-20.

Martinez, S., M. Hand, M. Da Pra, S. Pollack, K. Ralston, T. Smith, S. Vogel, et al. Local Food Systems: Concepts, Impacts, and Issues. Washington, DC: U.S. Department of Agriculture, Economic Research Service, Economic Research Report No. 97, 2010.

Muth, R.F. "Household Production and Consumer Demand Functions." Econometrica 34 (1966):699-708.

National Agricultural Statistics Service. Statistics of Hawaii Agriculture 2011.

Pirog, R., and N. McCann. Is Local Food More Expensive? A Consumer Price Perspective on Local and Non-Local Foods Purchased in Iowa. Ames, IA: Leopold Center for Sustainable Agriculture, Iowa State University, December 2009.

QSR. "Local Food Trend Prominent and Permanent." January 28, 2015. Internet site: http://www.qsrmagazine.com/news/local-food-trend-prominent-and-permanent (Accessed February 11, 2015).

Roheim, C.A., F. Asche, and J.I. Santos. "The Elusive Price Premium for Ecolabelled Products: Evidence from Seafood in the UK Market.” Journal of Agricultural Economics 62(2011):655-68.

Roheim, C.A., L. Gardiner, and F. Asche. "Value of Brands and Other Attributes: Hedonic Analysis of Retail Frozen Fish in the UK." Marine Resource Economics 22(2007):239_ 53.

Roosevelt, M. "Local-Food Movement: The Lure of the 100-Mile Diet." Time Magazine 167(2006):78.

Rosen, S. "Hedonic Prices and Implicit Markets: Product Differentiation in Pure Competition." Journal of Political Economy 82(1974):34-55.

Thilmany, D., C.A. Bond, and J.K. Bond. "Going Local: Exploring Consumer Behavior and Motivations for Direct Food Purchases." American Journal of Agricultural Economics 90(2008):1303-9.

Ulupono Initiative. "Local Food Market Demand Study Confirms That Hawaii Residents Want More Locally Grown Products and Are Willing to Pay More For It.” December 6, 2011. Internet site: http://ulupono.com/news_posts/local-food-market-demand-studyconfirms-that-hawai-i-residents-want-more-locally-grown-products-and-are-willing-topay-more-for-it (Accessed January 20, 2013).

Umberger, W.J., D.D. McFadden, and A.R. Smith. "Does Altruism Play a Role in Determining U.S. Consumer Preferences and Willingness to Pay for Natural and Regionally Produced Beef?" Agribusiness 25(2009):268-85.

Xu, X., M.K. Loke, and P. Leung. "Is There a Price Premium for Local Food? The Case of the Fresh Lettuce Market in Hawaii." Agricultural and Resource Economics Review 44(2015):110-23. 